\title{
Investigation of the anomalous action of 5-hydroxyresorcinol on tyrosinase.
}

\author{
by \\ Edward J Land, ${ }^{1}$ Christopher A Ramsden, ${ }^{1}$ Patrick A Riley, ${ }^{2}$ and Michael RL Stratford. ${ }^{3}$
}

1. Lennard Jones Laboratories, School of Physical and Geographical Sciences, Keele University, Keele, Staffordshire ST5 5BG, UK.

2. Totteridge Institute for Advanced Studies, The Grange, Grange Avenue, London N20 8AB, UK.

3. Oxford Institute for Radiation Oncology, Department of Oncology, University of Oxford, Oxford OX3 7DQ, UK.

Corresponding author: Professor P A Riley

Email: rebc900@ucl.ac.uk

Tel: (+44) 2084455687

Resorcinols have been much used as depigmenting agents in dermatology (Shimizu et al., 2000; Solano et al., 2006; Chang, 2009) but their mode of action has until recently been obscure. A series of studies of suicide inactivation of tyrosinase (Land et al., 2007; Land et al., 2008; Ramsden et al., 2009; Ramsden and Riley, 2010a; Ramsden and Riley, 2010b) demonstrated that the process requires monooxygenase (cresolase) activity and indicated the manner by which resorcinols act as inactivators of tyrosinase by altering the oxidation state of an active site copper atom (Ramsden and Riley, 2014a). A study of this process employing a series of substituted resorcinols gave results consistent with the proposed inactivation mechanism (Stratford et al., 2013). However, an unexpected exception was found in the case of 5-hydroxyresorcinol (5-HR) which, in contrast to other 5substituted resorcinols, not only failed to exhibit an inactivating effect but, on the contrary, appeared to be an activator of tyrosinase. We report here the results of our investigations of this strikingly anomalous behaviour.

This article has been accepted for publication and undergone full peer review but has not been through the copyediting, typesetting, pagination and proofreading process, which may lead to differences between this version and the Version of Record. Please cite this article as doi: $10.1111 / \mathrm{pcmr} .12490$

This article is protected by copyright. All rights reserved. 
In brief, we have shown that 5-HR (1) is not a substrate for tyrosinase, showing no oxygen utilisation, no alteration in spectral absorbance, no evidence of any product detectable by HPLC/MS, and no evidence of any diminution in tyrosinase activity on subsequent testing with known substrates such as 4-ethylphenol (EtP, 2) and 4-methoxyphenol (MOP). We have excluded the failure to act as a primary substrate due to a mechanism similar to that for hydroquinone, which involves a 1,2-benzoquinone to 1,4-benzoquinone tautomerism (Ramsden and Riley, 2014b). We have also demonstrated that 5-hydroxyresorcinol is not a secondary tyrosinase substrate since no oxidation of 5-hydroxyresorcinol takes place after tyrosinase activation by prior oxidation of 4-ethylphenol.

Experiments in which 5-HR-treated tyrosinase was exposed to EtP (2) showed the generation of a product absorbing at $450 \mathrm{~nm}$ not observed in the absence of 5-HR, associated with increased oxidation rate, diminished lag period and increased total oxygen utilisation. Similar results were obtained with MOP (see Table 1) implying that the enzyme is activated by a catechol. Since the formation of a catechol cannot be by a direct redox reaction with 5-HR, we propose that the $450 \mathrm{~nm}$ absorbing product is a compound derived from a 1,2-benzoquinone and 5-HR. We were able to confirm by pulse radiolysis using 4-ethylcatechol and 4-methoxycatechol that the $450 \mathrm{~nm}$-absorbing product in the presence of 5-HR was due to the rapid formation of an addition compound (rate constants $=0.08 \mathrm{sec}^{-1}$ and $0.13 \mathrm{sec}^{-1}$, respectively). This reaction did not occur under acidic conditions (pH 5.8) indicating that the reaction between 1,2-benzoquinones and 5-HR is base catalysed.

To identify the products of the addition reaction we examined the tyrosinase reaction system by HPLC/MS in the presence of equimolar 5-HR and EtP at $\mathrm{pH} 8.5$ and showed the generation of five major products (see Table 2). On the basis of their molecular weights and spectral absorption data we propose the formation of the products 4-9 as set out in Scheme 1. The initial addition products undergo redox exchange reactions and the resulting 1,2-benzoquinone products undergo ipsocyclisation to give 2,5-cyclohexadienones concordant with previous findings (Waiss et al., 1966; Crescenzi et al., 1991).

The reaction scheme (Scheme 1) shows the proposed reaction pathway which involves two addition reactions between 4-ethyl-1,2-benzoquinone (3) and 5-HR (1), and five redox exchange reactions with the 1,2-benzoquinone (3) generating 1,2-dihydroxy-4-ethylbenzene which acts as a catecholic substrate for tyrosinase. This accounts for the activation of met-tyrosinase, and hence the effect on the lag period (Ramsden and Riley, 2014a) and the additional oxygen utilisation. The calculated total oxygen stoichiometry according to the ratio of the products formed, based on the mean absorbances at $400 \mathrm{~nm}$, is 1.35 moles of oxygen per mole of EtP which corresponds closely with the data obtained (Table 1).

This article is protected by copyright. All rights reserved. 
We conclude that the 5-hydroxy group of 5-HR interferes with access to the active site of tyrosinase and further work may clarify the detailed molecular nature of this phenomenon. The major action of 5-HR is as a powerful trapping agent of 1,2-benzoquinones. Its observed influence in the presence of phenolic substrates on the characteristics of tyrosinase-catalysed oxidation, such as the lag period and maximum oxidation rate, is attributable to the formation of catecholic $\mathrm{C}$-addition products that function as secondary activating substrates for tyrosinase and which cyclise to form a range of unusual 2,5-cyclohexadienenones. These results explain how 5-hydroxyresorcinol acts as an activator of tyrosinase by enabling the generation of a catecholic substrate in a manner similar to the formation of dopa by redox exchange with the natural internal addition product, cyclodopa. The demonstration of this extraneous activation pathway suggests that the biological regulation of melanogenesis is sensitive to the availability of compounds able to form reductive addition compounds with 1,2benzoquinones.

Supplementary data associated with the experimental details of this work can be viewed in the online version at http://xxx

We thank Tomos Kempley for skilful technical assistance. The pulse radiolysis experiments were performed at the Paterson Institute for Cancer Research Free Radical Research Facility, Christie Hospital NHS Trust, Manchester, supported by the European Commission TMR Programme 'Access to Large-Scale Facilities'.

\section{References.}

Chang, T-S. (2009). An updated review of tyrosinase inhibitors. Int. J. Mol. Sci., 10, 2440-2475.

Crescenzi, O., Napolitano, A., Prota, G., Peter, M.G. (1991). Oxidative coupling of DOPA with resorcinol and phloroglucinol: isolation of adducts with an unusual tetrahydromethanobenzofuro[2,3- $d$ ] azocine skeleton. Tetrahedron 47, 6243-6350.

Land, E.J., Ramsden, C.A., Riley, P.A. (2007). The Mechanism of Suicide-Inactivation of Tyrosinase: A Substrate Structure Investigation. Tohoku J. Exp. Med., 212, 341-348.

Land, E.J., Ramsden, C.A., Riley, P.A., Stratford, M.R.L. (2008). Evidence Consistent with the Requirement of Cresolase Activity for Suicide Inactivation of Tyrosinase. Tohoku J.Exp. Med., 216, 231-238.

Ramsden, C.A., Riley, P.A. (2010a). Studies of the competing rates of catechol oxidation and suicide inactivation of tyrosinase. Arkivoc, $2010(x), 248-254$.

This article is protected by copyright. All rights reserved. 
Ramsden, C.A., Riley, P.A. (2010b). Mechanistic studies of tyrosinase suicide inactivation. Arkivoc, $2010(i), 260-274$.

Ramsden, C.A., Riley, P.A. (2014a). Tyrosinase: The four oxidation states of the active site and their relevance to enzymatic activation, oxidation and inactivation. Bioorg. Med. Chem. 22, 2388-2395.

Ramsden, C.A., Riley, P.A. (2014b). Mechanistic aspects of the tyrosinase oxidation of hydroquinone. Bioorg. Med. Chem. Letters, 24, 2463-2464.

Ramsden, C.A., Stratford, M.R.L., Riley, P.A. (2009). The influence of catechol structure on the suicide-inactivation of tyrosinase. Org. Biomol. Chem., 7, 3388-3390.

Shimizu, K., Kondo, R., Sakai, K. (2000). Inhibition of tyrosinase by flavonoids, stilbenes and related 4-substituted resorcinols: structure-activity investigations. Planta Med. 66, 11-15.

Solano, F., Briganti, S., Picardo, M., Ghanem, G. (2006). Hypopigmenting agents: an updated review of biological, chemical and clinical aspects. Pigment Cell Res., 19, 550-571.

Stratford, M.R.L., Ramsden, C.A., Riley, P.A. (2013). Mechanistic studies of the inactivation of tyrosinase by resorcinol. Bioorg. Med. Chem. 21, 1166-1173.

Waiss, A.C., Kuhnle, J.A., Windle, J.J., Wiersema, A.K. (1966). Oxidative condensation of catechols and resorcinols. Tetrahedron Letters 50, 6251-6255.

This article is protected by copyright. All rights reserved. 
Table 1. Summary of kinetic data from oxidation experiments.

\begin{tabular}{|c|c|c|c|c|c|}
\hline $\begin{array}{l}\text { Order of } \\
\text { addition }\end{array}$ & $\begin{array}{c}\text { substrate } \\
\text { (nmol) }\end{array}$ & $\begin{array}{l}\text { 5-HR } \\
(\mathrm{nmol})\end{array}$ & $\begin{array}{c}\text { Oxygen uptake } \\
\text { (nmol) }\end{array}$ & $\begin{array}{l}\text { Lag period } \\
\quad \text { (secs) }\end{array}$ & $\begin{array}{c}\text { Vmax } \\
\left(\text { nmol } \text { min }^{-1}\right)\end{array}$ \\
\hline 5-HR/EtP & 400 & 400 & 515 & 24 & 143 \\
\hline EtP/5-HR & 400 & 400 & 521 & 5 & 546 \\
\hline EtP/5-HR/5-HR/EtP & 800 & 400 & 720 & - & - \\
\hline MOP & 0 & 250 & 220 & 90 & 145 \\
\hline MOP/5-HR & 250 & 250 & 310 & - & - \\
\hline MOP/5-HR/MOP & 250 & 500 & 615 & 12 & 456 \\
\hline
\end{tabular}

Table 2. Summary of data from HPLC/MS experiments.

\begin{tabular}{|c|c|c|c|c|}
\hline $\begin{array}{c}\text { Retention } \\
\text { Time (mins) }\end{array}$ & $\begin{array}{c}\boldsymbol{m} / \mathbf{z} \\
(\mathbf{M + 1})\end{array}$ & $\begin{array}{c}\boldsymbol{\lambda}_{\max } \\
(\mathbf{n m})\end{array}$ & $\begin{array}{c}\text { Structure } \\
(\text { see Scheme 1) }\end{array}$ & $\begin{array}{c}\text { Peak area at 400 nm } \\
(\%)\end{array}$ \\
\hline 3.48 & 399 & 285 & $\mathbf{5}$ & 15 \\
\hline 4.35 & 261 & 418 & $\mathbf{4}$ & 31 \\
\hline 4.70 & 397 & 428 & $\mathbf{6}$ & 9 \\
\hline 4.88 & 397 & 428 & $\mathbf{7}$ & 14 \\
\hline 5.10 & 395 & 453 & $\mathbf{8 + 9}$ & 25 \\
\hline
\end{tabular}

This article is protected by copyright. All rights reserved. 
Scheme 1. Reactions between 5-HR (1) and EtP (2) in the presence of tyrosinase. The proposed identity of the products and their molecular weights are indicated. Redox reactions with 4-ethyl-1,2quinone (3) are followed by ipso-cyclization. Compounds not observed by chromatography are indicated in square brackets.

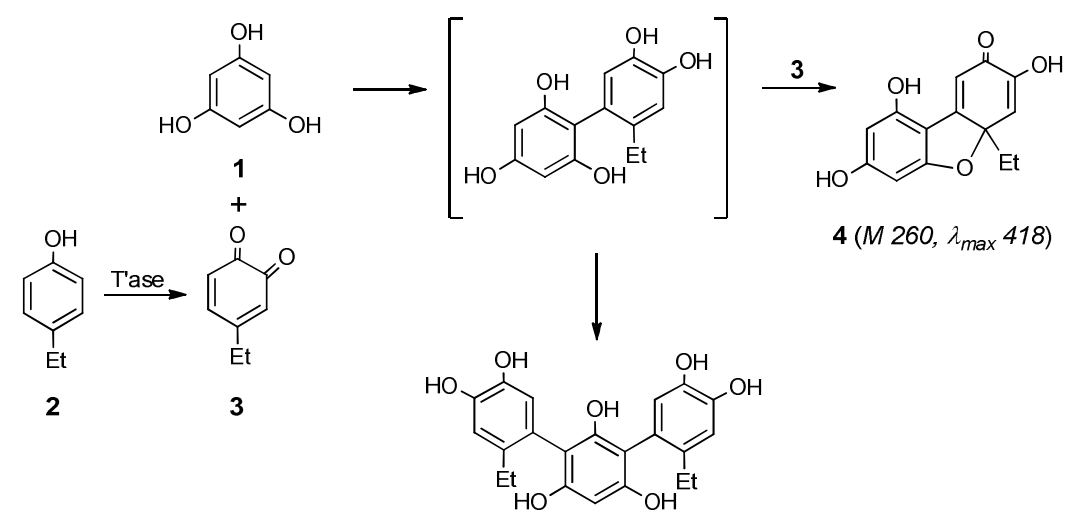

$5\left(M 398, \lambda_{\max } 285\right)$
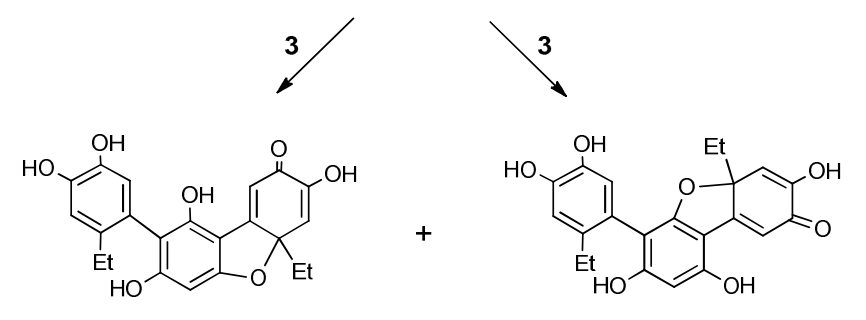

$6\left(M 396, \lambda_{\max } 428\right)$

$7\left(M 396, \lambda_{\max } 428\right)$
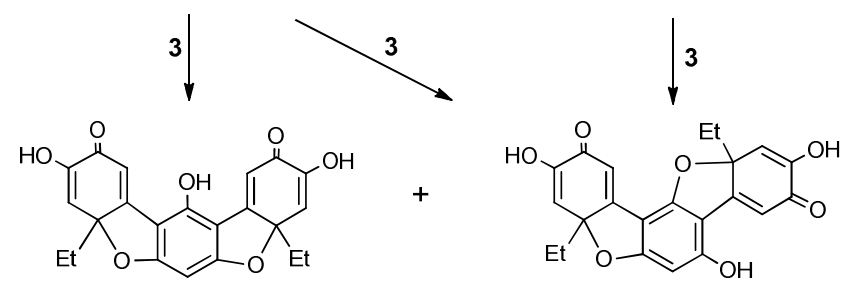

$8\left(M 394, \lambda_{\max } 453\right)$

$9\left(M 394, \lambda_{\max } 453\right)$

This article is protected by copyright. All rights reserved. 
This article is protected by copyright. All rights reserved. 